\title{
Epileptiform Activity During Rewarming from Moderate Cerebral Hypothermia in the Near-Term Fetal Sheep
}

\author{
LUELLA C. GERRITS, MALCOLM R. BATTIN, LAURA BENNET, HERNAN GONZALEZ, AND \\ ALISTAIR J. GUNN \\ University Medical Center [L.C.G.], St Radboud, 6500 HB Nijmegen, The Netherlands; Department of \\ Paediatrics [L.C.G., M.R.B., H.G., A.J.G.], Grafton, University of Auckland, Auckland, New Zealand; \\ Departments of Physiology and Obstetrics \& Gynaecology [L.C.G., L.B., A.J.G.], University of Auckland, \\ Auckland, New Zealand; and Facultad de Medicina [H.G.], Pontificia Universidad Catolica, Casilla \\ 13898, Santiago, Chile
}

\begin{abstract}
ABST
Moderate hypothermia is consistently neuroprotective after
hypoxic-ischemic insults and is the subject of ongoing clinical
trials. In pilot studies, we observed rebound seizure activity in
one infant during rewarming from a 72 -h period of hypothermia.
We therefore quantified the development of EEG-defined sei-
zures during rewarming in an experimental paradigm of delayed
cooling for cerebral ischemia. Moderate cerebral hypothermia $(n$
$=9)$ or sham cooling ( $n=13)$ was initiated 5.5 after
reperfusion from a 30 -min period of bilateral carotid occlusion in
near-term fetal sheep and continued for $72 \mathrm{~h}$ after the insult.
During spontaneous rewarming, fetal extradural temperature rose
from $32.5 \pm 0.6^{\circ} \mathrm{C}$ to control levels $\left(39.4 \pm 0.1^{\circ} \mathrm{C}\right)$ in $47 \pm 6$
min. Carotid blood flow and mean arterial blood pressure in-
creased transiently during rewarming. The cooling group showed
a significant increase in electrical seizure events 2,3 , and $5 \mathrm{~h}$
after rewarming, maximal at $2 \mathrm{~h}(2.9 \pm 1.2$ versus $0.5 \pm 0.5$
events/h; $p<0.05)$. From $6 \mathrm{~h}$ after rewarming, there was no
\end{abstract}
significant difference between the groups. Individual seizures were typically short $(28.8 \pm 5.8 \mathrm{~s}$ versus $29.0 \pm 6.8 \mathrm{~s}$ in sham cooled; NS), and of modest amplitude (35.9 \pm 2.8 versus $38.8 \pm$ $3.4 \mu \mathrm{V}$; NS). Neuronal loss in the parasagittal cortex was significantly reduced in the cooled group $(51 \pm 9 \%$ versus $91 \pm$ $5 \% ; p<0.002)$ and was not correlated with rebound epileptiform activity. In conclusion, rapid rewarming after a prolonged interval of therapeutic hypothermia can be associated with a transient increase in epileptiform events but does not seem to have significant adverse implications for neural outcome. (Pediatr Res 57: 342-346, 2005)

CaBF, carotid blood flow

\section{Abbreviations}

EAA, excitatory amino acid

HIE, hypoxic-ischemic encephalopathy
There is now consistent experimental evidence that a sufficient interval of moderate cerebral hypothermia started shortly after severe perinatal hypoxia-ischemia can reduce secondary neuronal injury and improve functional outcomes (1). Although only pilot data are available in newborn infants (2), early induction of moderate hypothermia in adult patients after cardiac arrest improves neurologic recovery $(3,4)$. Rewarming after cooling treatment for severe hypoxic-ischemic encephalopathy (HIE), however, is potentially a more complex process

Received June 1, 2004; accepted August 13, 2004.

Correspondence: Alistair J. Gunn, MBChB, Ph.D., Department of Physiology, Faculty of Medicine and Health Science, The University of Auckland, Private Bag 92019, Auckland, New Zealand; e-mail: aj.gunn@auckland.ac.nz

This study was supported by grants from the Health Research Council of New Zealand, Auckland Medical Research Foundation, the Lottery Grants Board of New Zealand, UPHS grant HD32752, and VSB Fonds and Stichting Nuffic.

Reprints will not be available from the author.

DOI: 10.1203/01.PDR.0000150801.61188.5F than the original induction of cooling: first because it might lead to destabilizing cardiovascular changes such as a loss of peripheral tone with an increased requirement for cardiac work (5) and second because damaging processes such as release of excitatory amino acid neurotransmitters that have been suppressed by hypothermia could become active again $(6,7)$.

In view of such considerations, clinical studies of therapeutic hypothermia typically have rewarmed infants at no more than $0.5^{\circ} \mathrm{C} / \mathrm{h}(8-10)$; however, there are few systematic data. During our early pilot studies of head-cooling with mild systemic hypothermia for neonatal HIE, we observed a case of an infant who exhibited transient clinical seizures during rewarming. To examine the hypothesis that rewarming from prolonged moderate hypothermia may be associated with rebound seizure activity, we quantified changes in numbers of epileptiform events and in their duration and intensity after rapid rewarming from a prolonged interval of in utero moderate hypothermia for 
cerebral ischemia in near-term fetal sheep. The sheep is a highly precocial species; thus, in terms of cerebral maturity and myelination, this gestational age is comparable to the human brain at term (11). We have previously reported the electrophysiologic, histologic, and blood changes in a subset of this group (12).

\section{METHODS}

In this study, we used the approach of selectively cooling the head to minimize the systemic complications associated with whole-body hypothermia (13). A chronically instrumented fetal preparation was used to test the effect of postinsult cooling; this is clearly a compromise as fetal and neonatal metabolism differ in several aspects. However, this approach provides a primary insult that occurs under fetal conditions, ensures stable control temperatures, and avoids anesthesia that might interact with hypothermia (14).

Surgical procedures. The experimental studies were approved by the Animal Ethics Committee of the University of Auckland. Romney/Suffolk fetal sheep from 117 to $124 \mathrm{~d}$ of gestation were operated on under $2 \%$ halothane/oxygen anesthesia as previously reported $(12,15)$. Polyvinyl catheters were inserted into both fetal brachial arteries and the amniotic sac. The vertebral-occipital anastomoses were ligated bilaterally to restrict vertebral blood supply to the carotid arteries. A double-ballooned inflatable occluder cuff was placed around each carotid artery along with a 3S-mm ultrasonic flow probe (Transonic Systems, Ithaca, NY) just proximal to the cuff. Two pairs of EEG electrodes (AS633-5SSF; Cooner Wire Co., Chatsworth, CA) were placed on the dura over the parasagittal parietal cortex $(5$ and $15 \mathrm{~mm}$ anterior and $10 \mathrm{~mm}$ lateral to the bregma), with a reference electrode sewn over the occiput. For measuring cortical impedance, a third pair of electrodes (Cooner Wire AS633-3SSF) was placed over the dura, $5 \mathrm{~mm}$ lateral to the EEG electrodes. A thermistor (Incu-Temp-1; Mallinckrodt Medical, St. Louis, MO) was placed over the parasagittal dura $20 \mathrm{~mm}$ anterior to the bregma; the burr holes were sealed, and the skin over the fetal skull was closed using cyanoacrylate glue.

A cooling coil, made from silicone tubing (Degania Silicone, Degania Bet, Israel), was attached over the dorsal surface of the scalp and extended over the lateral surface of the cranium down to the level of the external auditory meatus. A second thermistor (to measure fetal core body temperature) was placed in the fetal esophagus at the level of the right atrium. The fetus then was returned to the uterus, and all leads and catheters were exteriorized to the maternal flank. A polyvinyl catheter was placed in the maternal tarsal vein. After the operation, the ewes were housed in metabolic cages at constant temperature (16 \pm $\left.1{ }^{\circ} \mathrm{C}\right)$ and humidity $(50 \pm 10 \%)$, in a 12-h light/dark cycle, with free access to food and water. Gentamicin, $80 \mathrm{mg}$ i.v., was administered daily to the ewe for $5 \mathrm{~d}$.

Recordings. Fetal arterial blood pressure, corrected for amniotic fluid pressure (Novatrans II, MX860; Medex, Hilliard, OH), carotid arterial blood flows (T208 Ultrasonic Flowmeter; Transonic Systems), fetal extradural temperature, esophageal temperature, and fetal parietal EEG and impedance were recorded continuously. Recordings started at least $12 \mathrm{~h}$ before the experiment and continued for $120 \mathrm{~h}$ afterward. Signals were averaged at 1-min intervals and stored to disk by custom software (Labview for Windows; National Instruments Ltd, Austin, TX), running on an IBM compatible computer. The EEG signal was low-pass filtered at $30 \mathrm{~Hz}$, and then the intensity spectrum and impedance signal were extracted. The raw EEG signal was recorded for off-line detection of seizure events.

Experimental procedures. At least $3 \mathrm{~d}$ after surgery, reversible cerebral ischemia was induced by inflating the carotid cuffs bilaterally with sterile saline for $30 \mathrm{~min}$. Successful occlusion was confirmed by the onset of an isoelectric EEG signal within $30 \mathrm{~s}$ of inflation (16).

Fetuses were randomized to either cooling or sham cooling starting at $6 \mathrm{~h}$ after ischemia (i.e. $5.5 \mathrm{~h}$ after reperfusion) and continued until $72 \mathrm{~h}$. Cooling was performed by circulating cold water through the cooling coil; the initial water temperature was $6^{\circ} \mathrm{C}$ and then adjusted as necessary in the first $4 \mathrm{~h}$ to obtain an extradural temperature between 30 and $33^{\circ} \mathrm{C}$. In sham-cooled fetuses, the water was not circulated; thus, the cooling coil and its contents will have remained in equilibrium with fetal temperature. Fetuses were allowed to rewarm spontaneously after cooling was stopped. The fetuses were monitored for $48 \mathrm{~h}$ after the end of cooling, and then the ewe and the fetus were killed by an overdose of sodium pentobarbitone (9 g i.v. to the ewe; Pentobarb 300; Chemstock Int., Christchurch, New Zealand).

The fetal brain was perfusion-fixed in situ with $10 \%$ phosphate-buffered formalin. Predefined sections were selected according to the stereotaxic atlas for the immature fetal sheep. Neuronal loss was scored by light microscopy on
8- $\mu$ m-thick coronal sections stained with thionin and acid fuchsin by an assessor who was masked to the treatment group $(12,15)$. The proportion of neurons showing ischemic cell change in 48 preassigned areas in the parasagittal cortex was scored on a six-point scale: $0=$ no dead neurons; $5=$ $>0-10 \% ; 30=>10-50 \% ; 70=>50-90 \% ; 95=90-<100 \% ; 100=100 \%$ dead neurons. Average scores were calculated for each fetus.

Data analysis and statistics. Carotid blood flow $(\mathrm{CaBF})$ was calculated as the sum of the left and right measurements. CaBF is an index to cerebral blood flow, with a strong correlation with direct microsphere measurements $(17,18)$. Numbers of electrical seizure events were defined on EEG recordings from $6 \mathrm{~h}$ before rewarming to $24 \mathrm{~h}$ afterward in 13 sham-cooled and nine cooled fetuses. Seizure events were defined on raw EEG recordings by the presence of stereotypic evolving waveforms showing stereotypic increase and decrease in activity that lasted for $10 \mathrm{~s}$ or more and contained at least one peak of $20 \mu \mathrm{V}$ or greater, followed by a depression in EEG activity (19). When the raw EEG recording was not available (one of 13 sham-cooled animals and two of nine cooled animals), an electrical seizure event was defined on the 1-min EEG recording as a peak with a maximum of at least $10 \mu \mathrm{V}$ followed by a decrease in activity with a minimum of $10 \mu \mathrm{V}$ or less. The duration of seizure events was calculated on raw EEG recordings only.

The effect of rewarming on time-series analysis of physiologic data was performed off-line on the recorded signals, using hourly averages, by ANOVA (SPSS; SPSS Inc., Chicago, IL); time was treated as a repeated measure. The Mann-Whitney $U$ test was used to examine differences between groups in the frequency of electrical seizure events and histologic scores. Fisher exact test was used to examine changes in proportions. Regression analysis was used to examine the relationship between the increase in numbers of events in the 6-h period after rewarming to neuronal cell loss in the parasagittal region of the cortex. Data are mean \pm SEM.

\section{RESULTS}

In the cooled group, fetal extradural temperature rose from $32.5 \pm 0.6^{\circ} \mathrm{C}$ in the final $6 \mathrm{~h}$ of cooling to control levels $(39.4$ $\left.\pm 0.1^{\circ} \mathrm{C}\right)$ by $47 \pm 6 \mathrm{~min}$ after the start of rewarming $(p<$ 0.001 ; Fig. 1). Subsequently, there was a trivial level of overshoot of both extradural and esophageal temperatures compared with sham-cooled fetuses (to $39.7 \pm 0.1^{\circ} \mathrm{C}$ versus $39.5 \pm 0.1$; NS). There was a small increase in $\mathrm{CaBF}$ in the first hour after the start of rewarming compared with sham controls $(108.6 \pm 7.9$ versus $90.2 \pm 10.3 \mathrm{~mL} / \mathrm{min} ; p<0.05$; Fig. 1). Mean arterial blood pressure also showed a transient significant increase at 2 and $3 \mathrm{~h}$ after rewarming $(p<0.05)$. Although there was a small apparent rise in fetal heart rate in the first hour, this was not significant compared with sham controls (Fig. 1).

Rebound electrical seizure events were observed in five of nine cooled and only one of 13 sham-cooled animals $(p<0.05$, Fisher exact) during the first $6 \mathrm{~h}$ after rewarming (Fig. 2). The cooling group showed a significant increase in electrical seizure events 2,3 , and $5 \mathrm{~h}$ after rewarming, maximal at $2 \mathrm{~h}(2.9$ \pm 1.2 versus $0.5 \pm 0.5$ events $/ \mathrm{h} ; p<0.05$ ). From $6 \mathrm{~h}$ after rewarming, there was no significant difference between the groups. The duration of rebound seizure events was short, with an average of $28.8 \pm 5.8 \mathrm{~s}$ in the cooled and $28.9 \pm 6.8 \mathrm{~s}$ in the sham-cooled groups. Similarly, the amplitude of seizure events in the $6 \mathrm{~h}$ after rewarming was moderate and not different between the groups $(35.9 \pm 2.8$ versus $38.8 \pm 3.4$ $\mu \mathrm{V})$. Parasagittal neuronal cell loss was less in cooled fetuses than in controls (51 $\pm 9 \%$ versus $91 \pm 5 \% ; p<0.002)$, and there was no relationship between rebound seizure events and neuronal cell loss (Fig. 3).

\section{DISCUSSION}

This study demonstrates that $3 \mathrm{~d}$ after a severe ischemic insult that was treated with moderate cerebral hypothermia, 

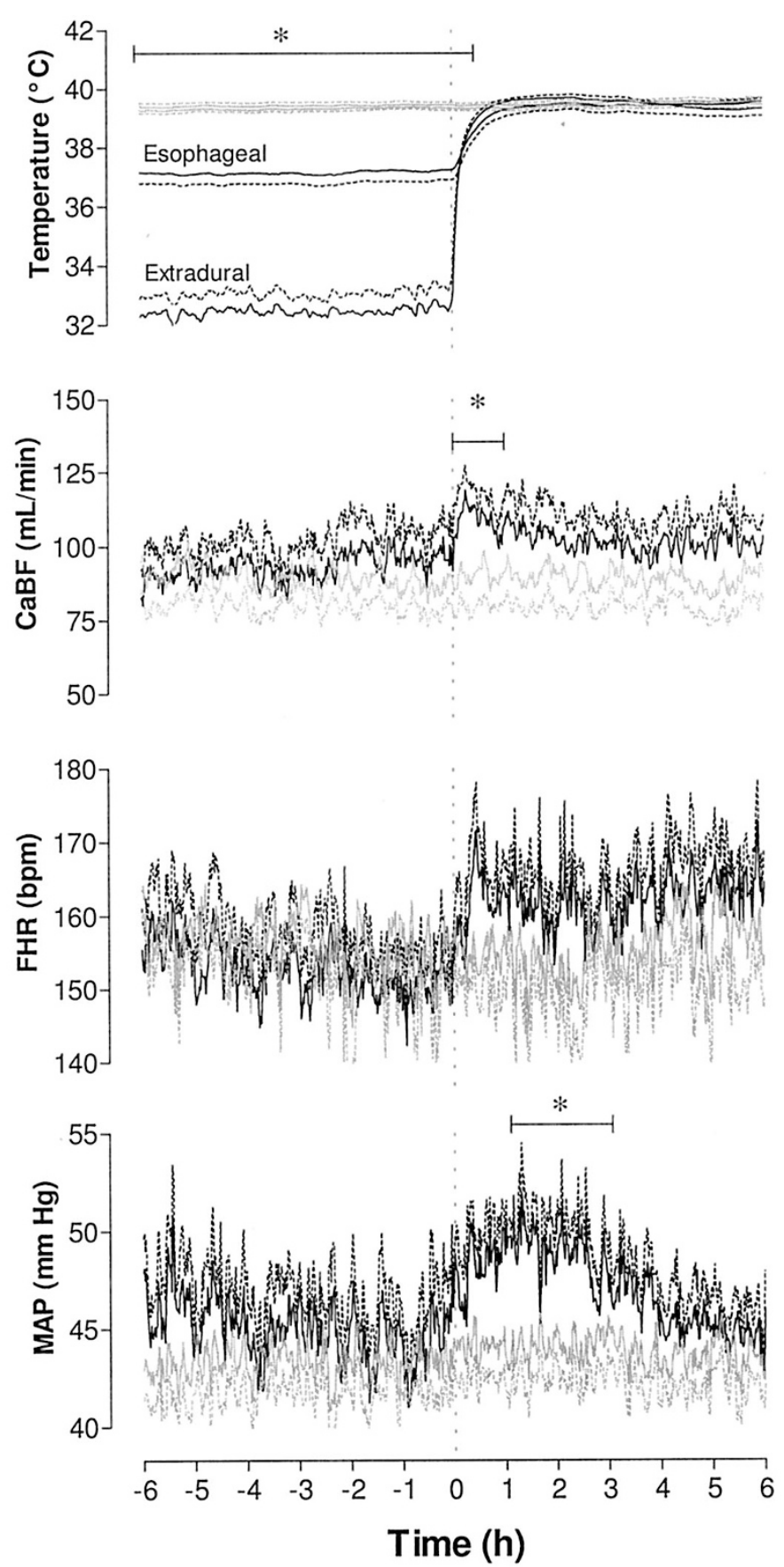

Figure 1. Time sequence of changes in extradural and esophageal temperatures, carotid blood flow $(\mathrm{CaBF})$, fetal heart rate (FHR; beats per minute), and mean arterial blood pressure (MAP) in sham-cooled (grey solid line; $n=13$ ) and cooled (black solid line; $n=9$ ) fetuses. The dashed lines indicate the respective SEMs. After the onset of rewarming at time 0 , shown by the vertical dotted lines, extradural temperature returned to control levels in $47 \pm 6 \mathrm{~min}$. Data are mean $\pm \mathrm{SEM} ;{ }^{*} p<0.05$.

rapid rewarming was associated with a significant but transient increase in EEG-defined seizure events and only mild systemic changes such as a transient increase in blood pressure and $\mathrm{CaBF}$. Seizures are common in both infants with $\operatorname{HIE}(2,9)$ and experimental models of neonatal HIE $(12,15)$. Although they typically are most severe in the first $24 \mathrm{~h}$ and resolve with time (15), some seizures may continue for many days. Thus, potentially, seizures that occur by coincidence during rewarming
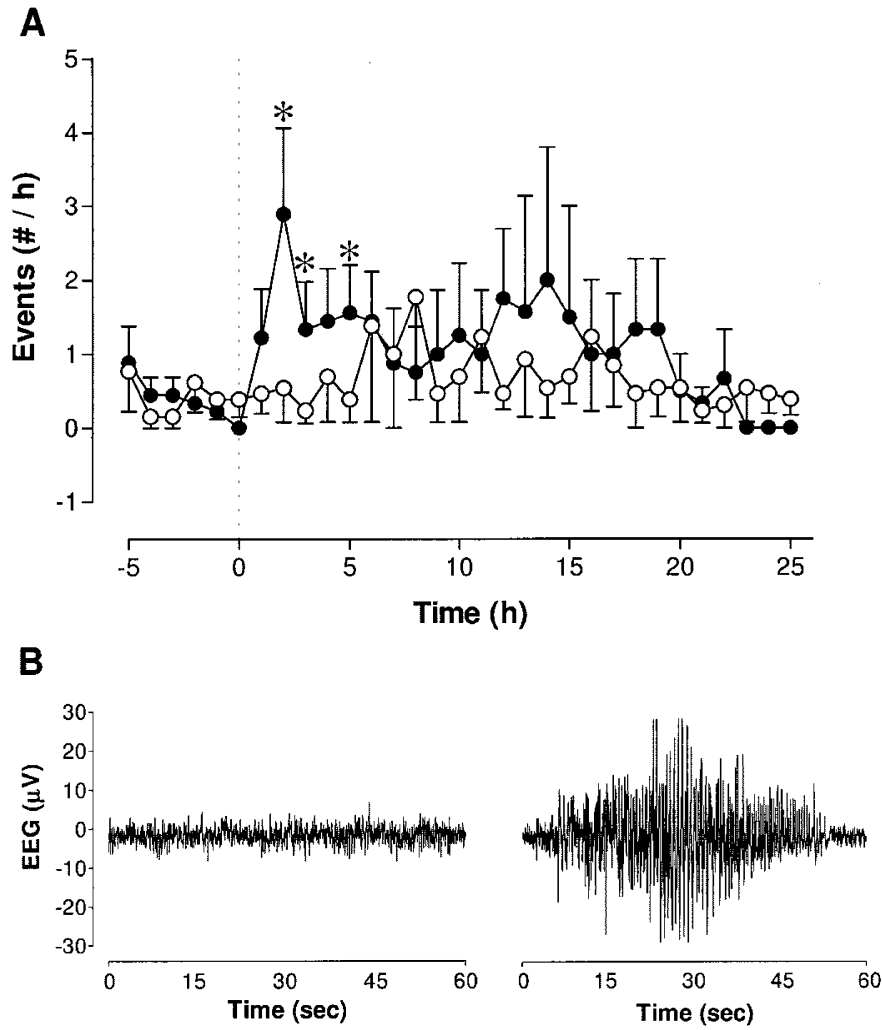

Figure 2. (A) Time sequence of changes in frequency of EEG-defined seizure events per hour. There was a significant increase in the frequency of events between 2 and $5 \mathrm{~h}$ after the start of rewarming in cooled fetuses $(-n=9)$ compared with sham-cooled fetuses $(\bigcirc ; n=13)$, which rapidly resolved to control values from 6 h. $* p<0.05$ (Mann Whitney $U$ test). (B) Examples of 1-min periods of raw EEG recordings from a cooled fetus. The left panel shows suppressed EEG, before the start of rewarming. The right panel shows a seizure event taken from the second hour after the start of rewarming.

could be confounded with "rebound" activity. We reported previously that seizure activity tends to be reduced during cooling (12). Combined with the observation of a transient increase in clinical seizures even after the much slower clinical rate of rewarming (over $3 \mathrm{~h}$ versus $45 \mathrm{~min}$ ) from head cooling with mild systemic hypothermia in an infant with evidence of HIE, the present data strongly suggest that rebound seizure activity can occur, at least occasionally. Nevertheless, it is important to note that the events were of similar, short duration as those that occurred in sham-cooled fetuses and that from $6 \mathrm{~h}$ after the start of rewarming onward, the frequency of events was not significantly different from controls. Critically, despite the presence of this rebound activity, significant neuroprotection was seen in the parasagittal region of the cortex, similar to our previous report in a subset of this cohort (12).

Although there are few data relating to the impact of rewarming after a period of prolonged cooling for preceding brain injury, there are suggestive data from studies of acute cooling. In adult dogs, rewarming from hypothermic cardiopulmonary bypass is associated with progressive recovery of normal continuous EEG activity (20); however, in this setting, there should seldom be underlying brain injury. In adult rats, although rapid rewarming over $30 \mathrm{~min}$ from moderate hypothermia was not associated with persistent biochemical or 


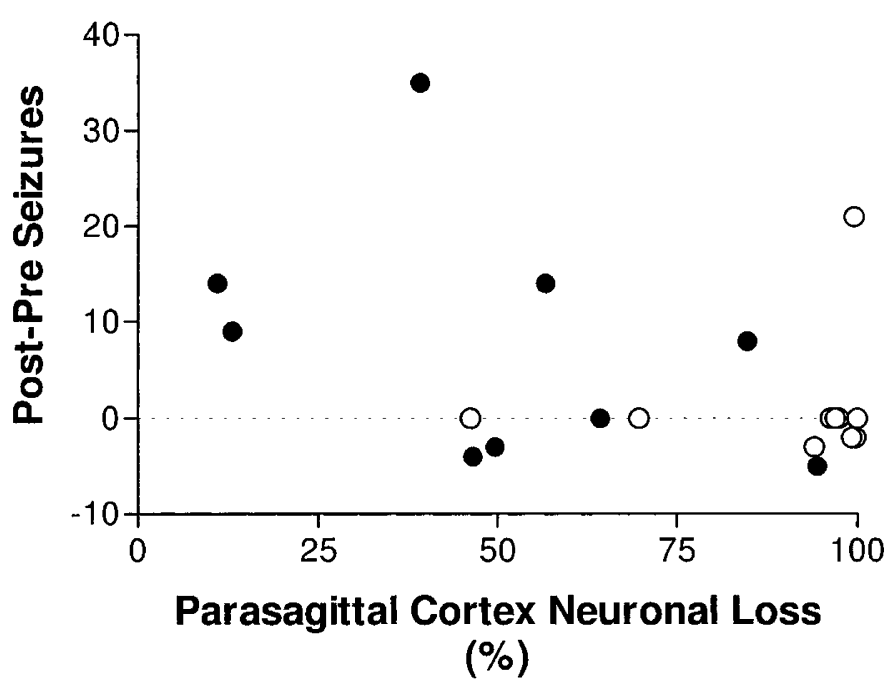

Figure 3. Relationship between rebound seizure events (total number of events in the 6-h interval after rewarming - total number of events in the $6 \mathrm{~h}$ before rewarming) and neuronal cell loss in the parasagittal cortex in shamcooled $(\bigcirc ; n=13)$ and cooled $(\bullet ; n=9)$ fetuses. There was no significant relationship between the number of rebound seizure events and the severity of neuronal cell loss after $5 \mathrm{~d}$ of recovery from ischemia $(r=-0.33, p=0.29)$.

behavioral changes (21), there were greater early changes in cardiac output and heart rate, in a similar pattern to the present study, compared with slower rewarming over $2 \mathrm{~h}$. Similarly, others have reported that rapid rewarming over $30 \mathrm{~min}$ can cause transient uncoupling of cerebral circulation and metabolism, with a transient increase in extracellular glutamate and lactate (22). Of greater concern, very rapid rewarming over 15 min after $1 \mathrm{~h}$ of hypothermia in adult rats can exacerbate traumatic axonal injury and impair cerebrovascular responsiveness, compared with slow rewarming over 90 min $(23,24)$. Although these studies used very short periods of hypothermia combined with faster rewarming than the mean of $47 \mathrm{~min}$ in our experimental study, they support the concept that very rapid rewarming can have undesirable physiologic and neural effects.

Several lines of evidence indicate that changes in brain temperature affect the generation of epileptiform activity. Hypothermia has been shown to directly reduce the rate of excitatory amino acid (EAA) neurotransmitter release during ischemic depolarization $(7,25)$, whereas posthypoxic cooling reduces EAA accumulation (26). Furthermore, hypothermia has potent postsynaptic effects on injured neurons as shown by the reduction in neuronal degeneration seen in vitro when hypothermia is started immediately after brief exposure to high concentrations of glutamate (27). Consistent with this, in the adult rat, hypothermia has been shown to increase the threshold for both flurothyl-induced status epilepticus and electroshock seizures $(28,29)$. Similarly, hypothermia after global hypoxiaischemia in the piglet was associated with reduced numbers of seizures (30). Thus, an increase in neuronal excitability during rewarming, coupled with loss of inhibition of EAA release, may have contributed to the transient increase in electrical events in the present study. Conversely, because hyperthermia can reduce the threshold for seizures (29), an overshoot in- crease in brain temperature after rewarming could be a possible contributor to rebound seizures. However, although there was a small increase in extradural temperatures over control values in the present study, it was not significant.

An alternative explanation is that the rebound seizures were a reflection of secondary deterioration that had been only temporarily interrupted or masked by hypothermia (31). This is unlikely to be a factor in the present study because there was no relationship between the occurrence or severity of rebound seizures in the first $6 \mathrm{~h}$ and the severity of neuronal loss in the underlying cortex $48 \mathrm{~h}$ after rewarming. Indeed, overall, there was significantly less damage in the hypothermia group, and the two cooled fetuses that showed the most rebound activity were among the least damaged. This indicates that one possible factor may simply be the presence of more surviving neurons that are able to exhibit epileptiform events. Evolving neural effects may extend for longer than the 5-d recovery from ischemia in the present study (32); thus, further longer term outcome studies would be necessary to confirm the present findings. Nevertheless, in adult rodents, persistent neuronal protection with hypothermia has been found 2-6 mo after ischemia $(33,34)$.

\section{CONCLUSION}

In conclusion, the present data demonstrate that a transient increase in electrical seizure events is not uncommon during very rapid rewarming in the experimental paradigm. From the clinical perspective, it is important to advise parents that this may occur; however, such activity does not seem to have any significant adverse implications for neurologic recovery or physiologic adaptation. Further studies are needed to test whether slower rewarming may reduce the incidence of rebound seizures.

\section{REFERENCES}

1. Gunn AJ, Bennet L 2002 Hypothermia in the management of hypoxic-ischemic encephalopathy. Neo Rev 3:e116-e122

2. Battin MR, Dezoete JA, Gunn TR, Gluckman PD, Gunn AJ 2001 Neurodevelopmental outcome of infants treated with head cooling and mild hypothermia after perinatal asphyxia. Pediatrics 107:480-484

3. Bernard SA, Gray TW, Buist MD, Jones BM, Silvester W, Gutteridge G, Smith K 2002 Treatment of comatose survivors of out-of-hospital cardiac arrest with induced hypothermia. N Engl J Med 346:557-563

4. The Hypothermia after Cardiac Arrest Study Group 2002 Mild therapeutic hypothermia to improve the neurologic outcome after cardiac arrest. N Engl J Med 346:549556

5. Thoresen M, Whitelaw A 2000 Cardiovascular changes during mild therapeutic hypothermia and rewarming in infants with hypoxic-ischaemic encephalopathy. Pediatrics 106:92-99

6. Stecker MM, Cheung AT, Pochettino A, Kent GP, Patterson T, Weiss SJ, Bavaria JE 2001 Deep hypothermic circulatory arrest: II. Changes in electroencephalogram and evoked potentials during rewarming. Ann Thorac Surg 71:22-28

7. Nakashima K, Todd MM 1996 Effects of hypothermia on the rate of excitatory amino acid release after ischemic depolarization. Stroke 27:913-918

8. Battin MR, Penrice J, Gunn TR, Gunn AJ 2003 Treatment of term infants with head cooling and mild systemic hypothermia $\left(35.0^{\circ} \mathrm{C}\right.$ and $\left.34.5^{\circ} \mathrm{C}\right)$ after perinatal asphyxia. Pediatrics 111:244-251

9. Shankaran S, Laptook A, Wright LL, Ehrenkranz RA, Donovan EF, Fanaroff AA, Stark AR, Tyson JE, Poole K, Carlo WA, Lemons JA, Oh W, Stoll BJ, Papile LA, Bauer CR, Stevenson DK, Korones SB, McDonald S 2002 Whole-body hypothermia for neonatal encephalopathy: animal observations as a basis for a randomized, controlled pilot study in term infants. Pediatrics 110:377-385

10. Azzopardi D, Robertson NJ, Cowan FM, Rutherford MA, Rampling M, Edwards AD 2000 Pilot study of treatment with whole body hypothermia for neonatal encephalopathy. Pediatrics 106:684-694

11. McIntosh GH, Baghurst KI, Potter BJ, Hetzel BS 1979 Foetal brain development in the sheep. Neuropathol Appl Neurobiol 5:103-114 
12. Gunn AJ, Gunn TR, Gunning MI, Williams CE, Gluckman PD 1998 Neuroprotection with prolonged head cooling started before postischemic seizures in fetal sheep. Pediatrics 102:1098-1106

13. Schubert A 1995 Side effects of mild hypothermia. J Neurosurg Anesthesiol 7:139147

14. Nakashima K, Todd MM 1996 Effects of hypothermia, pentobarbital, and isoflurane on postdepolarization amino acid release during complete global cerebral ischemia. Anesthesiology 85:161-168

15. Gunn AJ, Gunn TR, de Haan HH, Williams CE, Gluckman PD 1997 Dramatic neuronal rescue with prolonged selective head cooling after ischemia in fetal lambs. J Clin Invest 99:248-256

16. Williams CE, Gunn AJ, Synek B, Gluckman PD 1990 Delayed seizures occurring with hypoxic-ischemic encephalopathy in the fetal sheep. Pediatr Res 27:561-565

17. van Bel F, Roman C, Klautz RJ, Teitel DF, Rudolph AM 1994 Relationship between brain blood flow and carotid arterial flow in the sheep fetus. Pediatr Res 35:329-333

18. Bishai JM, Blood AB, Hunter CJ, Longo LD, Power GG 2003 Fetal lamb cerebral blood flow $(\mathrm{CBF})$ and oxygen tensions during hypoxia: a comparison of laser Doppler and microsphere measurements of CBF. J Physiol (Lond) 546:869-878

19. Scher MS, Hamid MY, Steppe DA, Beggarly ME, Painter MJ 1993 Ictal and interictal electrographic seizure durations in preterm and term neonates. Epilepsia 34:284-288

20. Lanier WL, Iaizzo PA, Murray MJ 1992 The effects of convective cooling and rewarming on systemic and central nervous system physiology in isofluraneanesthetized dogs. Resuscitation 23:121-136

21. Eshel G, Reisler G, Berkovitch M, Shapira S, Grauer E, Barr J 2002 Comparison of fast versus slow rewarming following acute moderate hypothermia in rats. Paediatr Anaesth 12:235-242

22. Nakamura T, Miyamoto O, Sumitani K, Negi T, Itano T, Nagao S 2003 Do rapid systemic changes of brain temperature have an influence on the brain? Acta Neurochir (Wien) 145:301-307
23. Suehiro E, Povlishock JT 2001 Exacerbation of traumatically induced axonal injury by rapid posthypothermic rewarming and attenuation of axonal change by cyclosporin A. J Neurosurg 94:493-498

24. Ueda Y, Suehiro E, Wei EP, Kontos HA, Povlishock JT 2004 Uncomplicated rapid posthypothermic rewarming alters cerebrovascular responsiveness. Stroke 35:601-606

25. Busto R, Globus MY, Dietrich WD, Martinez E, Valdes I, Ginsberg MD 1989 Effect of mild hypothermia on ischemia-induced release of neurotransmitters and free fatty acids in rat brain. Stroke 20:904-910

26. Thoresen M, Satas S, Puka-Sundvall M, Whitelaw A, Hallstrom A, Loberg EM, Ungerstedt U, Steen PA, Hagberg H 1997 Post-hypoxic hypothermia reduces cerebrocortical release of $\mathrm{NO}$ and excitotoxins. Neuroreport 8:3359-3362

27. Bruno VM, Goldberg MP, Dugan LL, Giffard RG, Choi DW 1994 Neuroprotective effect of hypothermia in cortical cultures exposed to oxygen-glucose deprivation or excitatory amino acids. J Neurochem 63:1398-1406

28. Swinyard EA, Toman JE 1948 Effects of alteration in body temperature on proportion of convulsive seizures in rats. Am J Physiol 154:207-210

29. Lundgren J, Smith ML, Blennow G, Siesjo BK 1994 Hyperthermia aggravates and hypothermia ameliorates epileptic brain damage. Exp Brain Res 99:43-55

30. Tooley JR, Satas S, Porter H, Silver IA, Thoresen M 2003 Head cooling with mild systemic hypothermia in anesthetized piglets is neuroprotective. Ann Neurol 53:65-72

31. Trescher WH, Ishiwa S, Johnston MV 1997 Brief post-hypoxic-ischemic hypothermia markedly delays neonatal brain injury. Brain Dev 19:326-338

32. Geddes R, Vannucci RC, Vannucci SJ 2001 Delayed cerebral atrophy following moderate hypoxia-ischemia in the immature rat. Dev Neurosci 23:180-185

33. Colbourne F, Corbett D 1995 Delayed postischemic hypothermia: a six month survival study using behavioral and histological assessments of neuroprotection. J Neurosci 15:7250-7260

34. Corbett D, Hamilton M, Colbourne F 2000 Persistent neuroprotection with prolonged postischemic hypothermia in adult rats subjected to transient middle cerebral artery occlusion. Exp Neurol 163:200-206 